\title{
A Fractional Programming Problem for Bank Asset and Liability Management
}

\author{
Ch. Ankhbayar, R. Enkhbat* \\ Business School, National University of Mongolia, Ulaanbaatar, Mongolia \\ Email: ^renkhbat46@yahoo.com
}

How to cite this paper: Ankhbayar, Ch. and Enkhbat, R. (2018) A Fractional Programming Problem for Bank Asset and Liability Management. iBusiness, 10, 119127. https://doi.org/10.4236/ib.2018.103007

Received: June 8, 2018

Accepted: August 10, 2018

Published: August 13, 2018

Copyright $\odot 2018$ by authors and Scientific Research Publishing Inc. This work is licensed under the Creative Commons Attribution International License (CC BY 4.0).

http://creativecommons.org/licenses/by/4.0/

\section{cc) (i) Open Access}

\begin{abstract}
The purpose of the paper is to present an Asset Liability Management (ALM) technique which uses a fractional programming model to determine the balance sheet of a commercial bank in Mongolia. We examine the balance sheet of a commercial bank introducing some common ratios used in the Bank. Numerical results were done in case of Mongolia in Central Bank.
\end{abstract}

\section{Keywords}

Asset and Liability Management, Banking, A Fractional Programming Problem

\section{Introduction}

Bank asset and liability management is defined as the simultaneous planning of all asset and liabilitypositions on the bank's balance sheet under consideration of the different bank management objectives and legal, managerial and market constraints, for the purpose of mitigating interest rate risk, providing liquidity and enhancing the value of the bank [1].

The central problem of ALM revolves around the bank's balance sheet and the main question is that what should be the composition of a bank's assets and liabilities on average given the corresponding returns and costs, in order to achieve certain goals, such as maximization of the bank's gross revenue. This need has led banks to determine their optimal balance among profitability, risk, liquidity and other uncertainties. The optimal balance between these factors cannot be found without considering important interactions that exist between the structure of a bank's liability and capital and the composition of its assets [2].

Looking to the past, asset and liability management models can be classified in several approaches [3]. The first, based on Markowitz's [4] theory of portfolio 
selection, assumes that returns are normally distributed and that bank managers utilize risk-averse utility functions. However, the model omits trading activity, matching assets and liabilities, transaction costs, and other similar features. The second approach is a linear programming model, proposed by Chambers and Charnes [5]. They were concerned with formulating, exploring and interpreting the use and construction which may be derived from a mathematical programming model which expresses more realistically than past efforts the actual conditions of current operations. However, this approach will not generate an optimal solution to the total problem, but rather acts as a deterministic simulation to observe portfolio behavior under various economic conditions [6].

The third approach is dynamic programming, proposed by Samuelson [7], Merton [8], and Eppen and Fama [9], who modeled of asset problems. These models are dynamic and account for the inherent uncertainty of the problem. However, given the small number of financial instruments that can be analyzed simultaneously, they are of limited use in practice. The fourth approach is a stochastic linear programming with simple recourse, which is also called linear programming under uncertainty. This technique explicitly characterizes each realization of the random variables by a constraint and leads to large problems in realistic situations. Cohen and Thore [10] viewed their model more as a tool for sensitivity analysis (in the aggregate) than a normative decision tool. The computational intractability and the perceptions of the formulation precluded consideration of problems other than those that were limited both in terms of time periods and in a number of variables and realizations.

The fifth, Eatman and Sealey [11] developed a multi-objective linear programming model for commercial bank balance sheet management considering profitability and solvency objectives subject to policy and managerial constraints. Indeed, Kusy and Ziemba [3] employed a multi-period stochastic linear program with simple recourse to model the management of assets and liabilities in banking while maintaining computational feasibility. Their results indicate that the proposed ALM model is theoretically and operationally superior to a corresponding deterministic linear programming model and that the computational effort required for its implementation is comparable to that of the deterministic model.

The sixth, Giokas and Vassiloglou [12] developed a goal-programming model for bank asset and liability management. Conventional linear programming is unable to deal with this kind of problem, as it can only handle a single goal in the objective function. Goal programming is the most widely used approach that solves large-scale multi-criteria decision making problem. Expansion of this approach is Kosmidou and Zopounidis [13] model, which determines the optimal balance among profitable, risk, liquidity and other uncertainties by considering several goals, such as the maximization of returns, the minimization of risk, the maintenance of a desirable level of liquidity and solvency, the expansion of deposits and loans. 
The last approach is stochastic integer programming problem proposed by Schultz and Tiedermann [14]. The logical constraints in the portfolio impose upper bounds on the number of classes of assets to be considered in the portfolio and the number of assets to be traded in any time period. They also force conditional lower bounds on the volume to be traded in periods. Then, they claim that the stochastic continuous programming problem is converted to a stochastic integer programming problem. Most authors consider the problem with only continuous variables, see Kouwenberg and Zenios [15], and Ziemba and Mulvey [16].

ALM models have been developed by a mixed approach since the 2006. Escudero and Garin [17] developed on multistage stochastic integer programming for incorporating logical constraints in asset and liability management under uncertainty, where the $0-1$ variables and the continuous variables appear at any stage. Zeng and $\mathrm{Li}[18]$ investigated continuous-time asset liability management under benchmark and mean-variance criteria in a jump diffusion market. The benchmark model was solved by employing the stochastic dynamic programming and its results are extended to the mean-variance model by adopting the duality theory. Mohammand and Sherafati [19] did an attempt to propose a model for optimizing liquidity management with goal programming perspective and integrating goal programming with fuzzy AHP.

The purpose of this paper is to develop a new type of a fractional programming problem for the bank asset liability management into a deterministic environment based on some common ratios.

\section{Problem Formulation}

The paper presents a new ALM methodology in a deterministic environment in order to choose strategic directions in a commercial bank's financial plan. The formulation is based on a balance sheet information and 14 structural variables. 7 variables correspond to assets and another 7 variables to liabilities. In Table 1, we show these variables.

In order to formulate our model, we need to introduce the following ratio variables as follows:

$$
\begin{gathered}
v_{1}=\frac{A_{1}+A_{2}+A_{3}+A_{4}}{L_{1}+L_{2}+L_{3}+L_{4}+L_{5}}, v_{2}=\frac{A_{5}}{A}, v_{3}=\frac{L_{2}}{L_{1}+L_{2}+L_{3}+L_{4}+L_{5}}, \\
v_{4}=\frac{A_{1}+A_{2}+A_{3}+A_{4}}{A}, v_{5}=\frac{L_{4}}{A}, v_{6}=\frac{A_{5}+A_{4}}{L_{1}+L_{2}+L_{3}}, v_{7}=\frac{A_{4}}{A}, \\
v_{8}=\frac{L_{1}+L_{3}}{L}, v_{9}=\frac{L_{4}}{L}, v_{10}=\frac{E}{L} .
\end{gathered}
$$

where $v_{1}$ : liquidity ratio, $v_{2}$ : total loans to total assets ratio, $v_{3}$ and $v_{8}$ : stability and instability ratio of deposit, respectively, $v_{4}$ : liquidity asset ratio, $v_{5}$ : due to banks and financial sector to total assets ratio, $v_{6}$ : earning assets to total assets ratio, $v_{7}$ : financial investment ratio, $v_{9}$ : due to banks and financial sector to total liabilities ratio, $V_{10}$ : capital sufficiency. 
Table 1. The decision variables.

\begin{tabular}{cc}
\hline Assets & Liabilities \\
\hline$A_{1}$ : Cash and cash equivalents & $L_{1}$ : Current account \\
$A_{2}$ : Deposits to the Bank of Mongolia & $L_{2}:$ Time deposit \\
$A_{3}$ : Deposits at other banks and financial sector & $L_{3}$ : Demand deposit \\
$A_{4}$ : Financial investments & $L_{4}:$ Due to banks and financial sector \\
$A_{5}:$ Loans and advances to customers & $L_{5}$ : Other deposits \\
$A_{6}$ : Other financial assets & $L_{6}$ : Other liabilities \\
$A_{7}$ : Fixed assets & $E$ : Equity \\
$A$ : Total assets & $L+E=A$ : Total assets \\
\hline
\end{tabular}

Remark 1. If asset and liability management committee approve, then the following inequalities hold:

$$
\begin{gathered}
L_{2} \leq L_{1}+L_{3}, L_{1}+L_{2} \geq L_{4}, A_{1}+A_{2}+A_{3}+A_{4} \geq L_{4}, L_{2} \leq A_{1}+A_{2}+A_{3}+A_{4}, \\
A_{5} \geq A_{1}+A_{2}+A_{3}+2 A_{4}, A_{6}+A_{7} \leq E, A_{6}+A_{7} \leq A_{4}, L_{5}+L_{6} \geq E .
\end{gathered}
$$

Remark 2. Based onremark 1, themain ratio variablessatisfy the following inequalities:

$$
\begin{gathered}
v_{1} \geq v_{4}, \quad v_{3} \leq v_{8}, \quad v_{6} \geq v_{2}+v_{7}, \quad v_{9} \geq v_{5}, \quad v_{8} \geq v_{9}, \\
v_{4} \geq v_{5}, \quad v_{3} \leq v_{4}, \quad v_{2} \geq v_{4}+v_{7} .
\end{gathered}
$$

Remark 3. It can be checked that if $A_{6}+A_{7} \leq A_{4}$ then $v_{2}+v_{4}+v_{7} \geq 1$.

Proof: Indeed, this implies from Remark 1 and Remark 2;

$$
\frac{A_{5}}{A}+\frac{A_{1}+A_{2}+A_{3}+A_{4}}{A}+\frac{A_{4}}{A}=1-\left(\frac{A_{6}+A_{7}-A_{4}}{A}\right) \geq 1 \text {. }
$$

Remark 4. If $L_{5}+L_{6} \geq E$ then $v_{3}+v_{8}+v_{9}+v_{10} \leq 1$.

Proof: Taking into account that $L=L_{1}+L_{2}+L_{3}+L_{4}+L_{5}+L_{6}$, we have

$$
\begin{aligned}
v_{3}+v_{8}+v_{9}+v_{10} & =\frac{L_{2}}{L_{1}+L_{2}+L_{3}+L_{4}+L_{5}}+\frac{L_{1}+L_{3}}{L}+\frac{L_{4}}{L}+\frac{E}{L} \\
& \approx \frac{L_{2}+L_{1}+L_{3}+L_{4}+E}{L}=\frac{L-L_{5}-L_{6}+E}{L} \\
& =1+\frac{E-L_{5}-L_{6}}{L} \leq 1 .
\end{aligned}
$$

Remark 5. If $A_{6}+A_{7} \leq E$ then

$$
v_{2}+v_{4} \geq \frac{v_{5}}{v_{9}} .
$$

Proof: We have the following obvious equalities and inequalities:

$$
\begin{aligned}
v_{2}+v_{4} & =\frac{A_{5}}{A}+\frac{A_{1}+A_{2}+A_{3}+A_{4}}{A}=\frac{A-\left(A_{6}+A_{7}\right)}{A} \\
& =1-\frac{A_{6}+A_{7}}{A} \geq 1-\frac{E}{A}=\frac{L}{A}=\frac{\frac{L_{4}}{A}}{\frac{L_{4}}{L}}=\frac{v_{5}}{v_{9}} .
\end{aligned}
$$




\section{Auxiliary Results}

Lemma1. For $v_{1}, v_{2}, \cdots, v_{9}$, we have

$$
v_{10}=\frac{v_{1}}{v_{3} v_{4}}\left(\frac{v_{9}}{v_{5}}\left(\frac{v_{2}+v_{7}}{v_{6}}\right)-v_{8}\right)-1 \text {. }
$$

Proof: For the variables $v_{1}, v_{3}, v_{4}, v_{5}, v_{6}$, we can write the following expression

$$
\frac{v_{1}}{v_{3} v_{4}}=\frac{\frac{A_{1}+A_{2}+A_{3}+A_{4}}{L_{1}+L_{2}+L_{3}+L_{4}+L_{5}}}{\frac{L_{2}}{L_{1}+L_{2}+L_{3}+L_{4}+L_{5}} \frac{A_{1}+A_{2}+A_{3}+A_{4}}{A}}=\frac{A}{L_{2}},
$$

and

$$
\frac{v_{9}}{v_{5}}=\frac{\frac{L_{4}}{L}}{\frac{L_{4}}{A}}=\frac{A}{L} .
$$

Indeed, denoting by $D=L_{1}+L_{2}+L_{3}$, we get

$$
\frac{v_{2}+v_{7}}{v_{6}}=\frac{\frac{A_{5}}{A}+\frac{A_{4}}{A}}{\frac{A_{5}+A_{4}}{D}}=\frac{D}{A}
$$

Substituting all above expressions into formula of $v_{10}$, we have

$$
\begin{aligned}
v_{10} & =\frac{A}{L_{2}}\left(\frac{A}{L} \frac{D}{A}-\frac{L_{1}+L_{3}}{L}\right)-1 \\
& =\frac{A}{L_{2}}\left(\frac{L_{1}+L_{2}+L_{3}}{L}-\frac{L_{1}+L_{3}}{L}\right)-1=\frac{A}{L}-1=\frac{E}{L} .
\end{aligned}
$$

Lemma 2. For $v_{1}, v_{2}, \cdots, v_{9}$, we have the connection:

$$
v_{1}=\frac{v_{4} v_{3}}{\frac{v_{2}+v_{7}}{v_{6}}-\frac{v_{8} v_{5}}{v_{9}}} .
$$

Proof: From the definition of $v_{1}$, we have

$$
v_{1}=\frac{A_{1}+A_{2}+A_{3}+A_{4}}{L_{1}+L_{2}+L_{3}+L_{4}+L_{5}} \frac{A}{A} \frac{L_{2}}{L_{2}}=v_{4} v_{3} \frac{A}{L_{2}} .
$$

If we use $D=L_{1}+L_{2}+L_{3}$, then $L_{2}$ is expressed as

$$
\begin{aligned}
L_{2} & =D-L_{3}-L_{1}=\frac{A_{5}+A_{4}}{v_{6}}-L_{3}-L_{1} \\
& =\frac{A}{v_{6}} \frac{A_{5}+A_{4}}{A}-L \frac{L_{3}+L_{1}}{L}=\frac{A}{v_{6}}\left(v_{2}+v_{7}\right)-L v_{8} .
\end{aligned}
$$

Consequently, we have

$$
v_{1}=v_{4} v_{3} \frac{A}{\frac{A}{v_{6}}\left(v_{2}+v_{7}\right)-L v_{8}}=\frac{v_{4} v_{3}}{\frac{1}{v_{6}}\left(v_{2}+v_{7}\right)-\frac{L}{A} \frac{L_{3}}{L_{3}} v_{8}}=\frac{v_{4} v_{3}}{\frac{v_{2}+v_{7}}{v_{6}}-\frac{v_{8} v_{5}}{v_{9}}} .
$$


which proves the lemma.

Lemma 3. For $v_{5}, v_{9}$, we have

$$
\frac{v_{5}}{v_{9}}=\frac{1}{1+v_{10}} .
$$

Proof: Substituting to $v_{5}, v_{9}$,

$$
\frac{v_{9}}{v_{5}}=\frac{A}{L}=\frac{1}{1-\frac{E}{L} \frac{L}{A}}=\frac{1}{1-v_{10} \frac{v_{5}}{v_{9}}},
$$

If reducing it, then proves the lemma.

Lemma 4. If $L_{6} / A \geq 0$, then

$$
-\frac{v_{4}}{v_{1}}+\frac{1}{1+v_{10}} \geq 0
$$

Proof: Substituting to $v_{10}$,

$$
E=v_{10}\left(L_{1}+L_{2}+L_{3}+L_{4}+L_{5}+L_{6}\right)=v_{10}(A-E),
$$

and we obtain

$$
\frac{E}{A}=\frac{v_{10}}{1+v_{10}} .
$$

In other words,

$$
\frac{L_{1}+L_{2}+L_{3}+L_{4}+L_{5}+L_{6}}{A}=1-\frac{v_{10}}{1+v_{10}},
$$

or

$$
\frac{L_{1}+L_{2}+L_{3}+L_{4}+L_{5}}{A}=\frac{v_{4}}{v_{1}},
$$

Then, we get proof the lemma.

\section{Formulation of a Fractional Programming}

Now we consider the problem of maximizing a capital sufficiency subject to liquidity ratio, leverage, liquidity asset ratio and loan portfolio ratio, total deposits ratio, total liabilities ratio, and combine ratio.

$$
f=\frac{v_{1} v_{2} v_{9}+v_{1} v_{7} v_{9}-v_{1} v_{5} v_{6} v_{8}-v_{3} v_{4} v_{5} v_{6}}{v_{3} v_{4} v_{5} v_{6}} \rightarrow \text { max }
$$

subject to constraints:

$$
\begin{gathered}
g_{1}=v_{1} v_{2} v_{9}+v_{1} v_{7} v_{9}-v_{1} v_{5} v_{6} v_{8}-v_{3} v_{4} v_{6} v_{9}=0, \\
g_{2}=\frac{v_{5}}{v_{9}}-\frac{v_{3} v_{4} v_{5} v_{6}}{v_{1} v_{2} v_{9}+v_{1} v_{7} v_{9}-v_{1} v_{5} v_{6} v_{8}}=0, \\
g_{3}=v_{2}+v_{4}-\frac{v_{5}}{v_{9}} \geq 0 \\
g_{4}=\frac{v_{4}}{v_{1}}-\frac{v_{3} v_{4} v_{5} v_{6}}{v_{1} v_{2} v_{9}+v_{1} v_{7} v_{9}-v_{1} v_{5} v_{6} v_{8}} \leq 0,
\end{gathered}
$$




$$
\begin{gathered}
g_{5}=v_{3}+v_{8}+v_{9}+\frac{v_{1} v_{2} v_{9}+v_{1} v_{7} v_{9}-v_{1} v_{5} v_{6} v_{8}-v_{3} v_{4} v_{5} v_{6}}{v_{3} v_{4} v_{5} v_{6}}-1 \leq 0, \\
\left(\begin{array}{ccccccccc}
-1 & 0 & 0 & 1 & 0 & 0 & 0 & 0 & 0 \\
0 & 0 & 1 & 0 & 0 & 0 & 0 & -1 & 0 \\
0 & 1 & 0 & 0 & 0 & -1 & 1 & 0 & 0 \\
0 & 0 & 0 & 0 & 1 & 0 & 0 & 0 & -1 \\
0 & 0 & 0 & 0 & 0 & 0 & 0 & -1 & 1 \\
0 & 0 & 0 & -1 & 1 & 0 & 0 & 0 & 0 \\
0 & 0 & 1 & -1 & 0 & 0 & 0 & 0 & 0 \\
0 & -1 & 0 & 1 & 0 & 0 & 1 & 0 & 0
\end{array}\right)\left(\begin{array}{l}
v_{1} \\
v_{2} \\
v_{3} \\
v_{4} \\
v_{5} \\
v_{6} \\
v_{7} \\
v_{8} \\
v_{9}
\end{array}\right) \leq\left(\begin{array}{l}
0 \\
0 \\
0 \\
0 \\
0 \\
0 \\
0 \\
0
\end{array}\right) \\
\underline{v}_{1} \leq v_{1} \leq \bar{v}_{1}, \underline{v}_{2} \leq v_{2} \leq \bar{v}_{2}, \underline{v}_{3} \leq v_{3} \leq \bar{v}_{3}, \\
\underline{v}_{4} \leq v_{4} \leq \bar{v}_{4}, \underline{v_{5}} \leq v_{5} \leq \bar{v}_{5}, \underline{v}_{6} \leq v_{6} \leq \bar{v}_{6}, \\
\underline{v}_{8} \leq v_{8} \leq \bar{v}_{8}, \underline{v}_{9} \leq v_{9} \leq \bar{v}_{9} .
\end{gathered}
$$

where $f$. capital sufficiency from lemma $1, g_{1}$ : liquidity ratio from lemma $2, g_{2}$ : leverage from lemma $3, g_{3}$ : liquidity asset ratio and loan portfolio ratio from remark $5, g_{4}$ : total deposits ratio from lemma $4, g_{5}$ : total liabilities ratio from remark 4 , and $g_{6}$ : combine ratio from remark 3 .

\section{Numerical Results}

The common ratio variables used in the specification of this model were taken directly as end of 2017 balance sheet of Top 5 commercial banks of Mongolia. We have shown the formulations below in Table 1, how to calculate these common ratios. Indeed, in Table 2 , results are showed by calculation variables.

Top 5 commercial banks in Mongolia shares 86 percent of a commercial bank market. We have ranked highest to lowest in Table 2. The ratio variables are difference due to specific of the commercial banks. The last columns of this table are mean and standard deviation calculated by the common ratio variables of Top 5 commercial banks.

We use the following formulation to calculate upper and lower bound of this fractional programming model:

$$
\begin{gathered}
\bar{v}_{i}=\text { mean }(i)+0.5 \cdot \operatorname{stdev}(i), \\
\underline{v}_{i}=\text { mean }(i)-0.5 \cdot \operatorname{stdev}(i), \\
i=\overline{1,9} .
\end{gathered}
$$

According to the formulation, the bounds found as follows:

$$
\begin{aligned}
& 0.483 \leq v_{1} \leq 0.544,0.432 \leq v_{2} \leq 0.507,0.340 \leq v_{3} \leq 0.429, \\
& 0.424 \leq v_{4} \leq 0.474,0.188 \leq v_{5} \leq 0.287,1.025 \leq v_{6} \leq 1.381, \\
& 0.122 \leq v_{7} \leq 0.211,0.203 \leq v_{8} \leq 0.281,0.209 \leq v_{9} \leq 0.312 .
\end{aligned}
$$


Table 2. The calculation variables.

\begin{tabular}{cccccccc}
\hline Ratios & Khan & TDB & XAC & State & Golomt & Mean & Stdev \\
\hline$V_{1}$ & 0.564 & 0.520 & 0.545 & 0.409 & 0.528 & 0.513 & 0.061 \\
$V_{2}$ & 0.457 & 0.403 & 0.442 & 0.599 & 0.445 & 0.469 & 0.075 \\
$V_{3}$ & 0.405 & 0.253 & 0.358 & 0.496 & 0.412 & 0.385 & 0.089 \\
$V_{4}$ & 0.477 & 0.452 & 0.483 & 0.362 & 0.472 & 0.449 & 0.050 \\
$V_{5}$ & 0.202 & 0.203 & 0.413 & 0.181 & 0.186 & 0.237 & 0.099 \\
$V_{6}$ & 0.998 & 1.648 & 1.522 & 0.988 & 0.859 & 1.203 & 0.356 \\
$V_{7}$ & 0.150 & 0.296 & 0.206 & 0.064 & 0.118 & 0.166 & 0.089 \\
$V_{8}$ & 0.300 & 0.232 & 0.116 & 0.251 & 0.311 & 0.242 & 0.078 \\
$V_{9}$ & 0.228 & 0.232 & 0.442 & 0.197 & 0.201 & 0.260 & 0.103 \\
$V_{10}$ & 0.129 & 0.140 & 0.070 & 0.089 & 0.081 & 0.102 & 0.031 \\
\hline
\end{tabular}

Source: Audited report of individual commercial bank.

Optimal solutions found by MATLAB were $v_{10}^{*}=0.092 v_{1}^{*}=0.522, v_{2}^{*}=0.502$, $v_{3}^{*}=0.340, v_{4}^{*}=0.429, v_{5}^{*}=0.208, v_{6}^{*}=1.232, v_{8}^{*}=0.281$ and $v_{9}^{*}=0.239$.

\section{Concluding Remarks}

The problem of maximizing a capital sufficiency subject to the ratios of the bank indicators for the first time has been formulated a fractional programming problem. The problem is nonconvex hard optimization problem. Solution of this problem is very suitable for realistic situation and the bank asset and liability management can describe where we are going on the market by analyzing competition impacts.

\section{Conflicts of Interest}

The authors declare no conflicts of interest regarding the publication of this paper.

\section{References}

[1] Gup, B.E. and Brooks, R. (1993) Interest Rate Risk Management. Irwin Professional Publishing, Burr Ridge.

[2] Kosmidou, K. and Zopounidis, C. (2008) Generating Interest Rate Scenarios for Bank Asset Liability Management. Optimization Letters, 2, 157-169. https://doi.org/10.1007/s11590-007-0050-9

[3] Kusy, I.M. and Ziemba, T.W. (1986) A Bank Asset and Liability Management Model. Operations Research, 34, 356-376. https://doi.org/10.1287/opre.34.3.356

[4] Markowitz, H.M. (1959) Portfolio Selection, Efficient Diversification of Investments. John Wiley \& Sons, New York.

[5] Chambers, D. and Charnes, A. (1961) Inter-Temporal Analysis and Optimization of Bank Portfolios. Management Science, 7, 393-410. https://doi.org/10.1287/mnsc.7.4.393 
[6] Birge, J.R. (1983) The Value of the Stochastic Solution in Stochastic Linear Programs with Fixed Recourse. Mathematical Programming, 24, 314-325. https://doi.org/10.1007/BF01585113

[7] Samuelson, P. (1969) Lifetime Portfolio Selection by Dynamic Stochastic Programming. Review of Economics and Statistics, 8, 239-246.

[8] Merton, R.C. (1969) Lifetime Portfolio Selection under Certainty: Continuous Time Case. Review of Economics and Statistics, 3, 373-413.

[9] Eppen, G.D. and Fama, E. F. (1971) Three Asset Cash Balance and Dynamic Portfolio Problems. Management Science, 17, 311-319.

https://doi.org/10.1287/mnsc.17.5.311

[10] Cohen, K.J. and Thore, S. (1970) Programming Bank Portfolio under Uncertainty. Journal of Bank Research, 2, 28-40.

[11] Eatman, L. and Sealey, Jr. (1979) A Multi-Objective Linear Programming Model for Commercial Bank Balance Sheet Management. Journal of Bank Research, 9, 227-236.

[12] Giokas, D. and Vassiloglou, M. (1991) A Goal Programming Model for Bank Assets and Liabilities. European Journal of Operations Research, 50, 48-60. https://doi.org/10.1016/0377-2217(91)90038-W

[13] Kosmidou, K. and Zopounidis, C. (2002) A Multi-Objective Methodology for Bank Asset Liability Management. In: Pardalos, P.M. and Tsitsiringos, V.K., Eds., Financial Engineering, E-Commerce and Supply Chain, Kluwer Academic Publishers, Alphen aan den Rijn, 139-151.

[14] Schultz, R. and Tiedemann, S. (2004) Risk Aversion via Excess Probabilities in Stochastic Programs with Mixed-Integers Recourse. SIAM Journal on Optimization, 14, 115-138. https://doi.org/10.1137/S1052623402410855

[15] Kouwenberg, R. and Zenios, S. (2006) Stochastic Programming Models for Asset Liability Management. Handbook of Asset and Liability Management, Vol. 1. North-Holland, Amsterdam, 253-303.

[16] Ziemba, W. and Mulvey, J. (1998) Worldwide Asset and Liability Modeling. Cambridge University Press, London.

[17] Escudero, L.F. and Garin, A. (2009) On Multistage Stochastic Integer Programming for Incorporating Logical Constraints in Asset and Liability Management under Uncertainty. Computer Management Science, 6, 307-327. https://doi.org/10.1007/s10287-006-0035-7

[18] Zeng, Y. and Li, Z. (2011) Asset Liability Management under Benchmark and Mean-Variance Criteria in a Jump Diffusion Market. Journal of Systems Science and Complex, 24, 317-327. https://doi.org/10.1007/s11424-011-9105-1

[19] Mohammandi, R. and Sherafati, M. (2015) Optimization of Bank Liquidity Management Using Goal Programming and Fuzzy AHP. Research Journal of Recent Sciences, 4, 53-61. 